\title{
Synapse specificity of long-term potentiation breaks down with aging
}

\author{
Laurence Ris and Emile Godaux ${ }^{1}$ \\ Laboratory of Neurosciences, University of Mons-Hainaut, 7000 Mons, Belgium
}

\begin{abstract}
Memory shows age-related decline. According to the current prevailing theoretical model, encoding of memories relies on modifications in the strength of the synapses connecting the different cells within a neuronal network. The selective increases in synaptic weight are thought to be biologically implemented by long-term potentiation (LTP). Here, we report that tetanic stimulation of afferent fibers in slices from 12-mo-old mice triggers an LTP not restricted to the activated synapses. This phenomenon, which can be anticipated to hinder memory encoding, is suppressed by blocking either L-type $\mathrm{Ca}^{++}$channels or $\mathrm{Ca}^{++}$-induced $\mathrm{Ca}^{++}$release, both well known to become disregulated with aging.
\end{abstract}

During the normal aging process, humans and animals experience age-related memory decline (Bach et al. 1999; Rosenzweig and Barnes 2003). Historically, it was thought that the primary contribution to the etiology of this decline was a massive loss of neurons in all the cortical layers and in the hippocampus (Brody 1955; Scheibel et al. 1976; Scheibel 1979). However, when it became possible to eliminate many of the confounding factors of the previous studies, this was proved to be a misconception (Burke and Barnes 2006). Nowadays, a great number of studies have identified multiple changes in $\mathrm{Ca}^{++}$-related electrophysiological processes as consistent biomarkers of aging (Landfield and Pitler 1984; Thibault and Landfield 1996; Norris et al. 1998; Thibault et al. 2001; Gant et al. 2006). One of the current prevailing hypotheses is that those $\mathrm{Ca}^{++}$dysregulations underlie many aspects of aging. However, the potential link between agerelated $\mathrm{Ca}^{++}$dysregulations and memory decline is still missing.

For neurocomputing theorists, every memory is encoded in a neuronal network thanks to a change in the distribution of its synaptic weights (Zipser and Andersen 1988). Among the possible biological mechanisms, long-term potentiation (LTP) is the favored candidate to be at the basis of memory storage because this activity-induced increase in synaptic strength is (1) durable and (2) input-selective (restricted to the activated synapses). In the hippocampal synapses between Schaffer collaterals and CA1 pyramidal neurons, a single train of tetanic stimulation triggers a short-lasting LTP (S-LTP), which lasts $1-2 \mathrm{~h}$, whereas multiple trains induce a long-lasting LTP (L-LTP) lasting $>4 \mathrm{~h}$ (Huang and Kandel 1994; Abel et al. 1997). Potential age-related LTP defects have been sought out in the past. It has been reported that S-LTP in area CA1 from aged animals was normal when supra-threshold stimulation parameters were used (Moore et al. 1993; Burke and Barnes 2006) and showed deficits only when peri-threshold stimulation was applied (Barnes et al. 1992; Burke and Barnes 2006). The L-LTP triggered by multiple trains has been reported to be decreased in aged mice (18 mo) (Bach et al. 1999). In contrast, a brief $1-\mathrm{Hz}$ paired-pulse stimulation has been found to induce an L-LTP in old mice but not in young animals (Huang and Kandel 2006). In our work, we focused on the effect of aging on another aspect of LTP: its input selectivity.

The experiments were performed on transverse hippocampal slices (400- $\mu \mathrm{m}$ thickness) from C57BL/6 mice ( 2 and 12 mo old), prepared as described by Nguyen and Kandel (1997). All the

'Corresponding author.

E-mail emile.godaux@umh.ac.be; fax 32-65-373573.

Article is online at http://www.learnmem.org/cgi/doi/10.1101//m.451507. experiments were carried out in accordance with National Institutes of Health regulations for the care and use of animals in research and with local ethics committee guidelines. The hippocampus was isolated and sliced using a Mcllwain chopper. Field excitatory postsynaptic potentials (fEPSPs) were recorded with a glass microelectrode (2-5 Mohm, filled with ACSF) positioned in the stratum radiatum of area CA1. Two bipolar nickel chromium stimulating electrodes were used to elicit fEPSPs by stimulating Schaffer collateral fibers. LTP was induced electrically by applying four 1 -sec trains $(100 \mathrm{~Hz}$, test strength) spaced 5 min apart.

Two groups of mice ( 2 and 12 mo old) were compared. First, we established the input-output relationships in the two age groups by plotting the slope of the fEPSP as a function of the fiber volley size (Fig. 1A). The slopes of the fEPSP were lower in mice aged 12 mo (two-way ANOVA, $F_{(1,9)}=115, P<0.001$ ), which suggests a loss of synapses, either anatomical or functional (Landfield et al. 1986; Barnes et al. 1992; Deupree et al. 1993). Next, we triggered LTP using four trains of tetanic stimulation. Four hours after induction, the fEPSP amplitudes were not different in the two groups (168 $\pm 10 \%$ of baseline in 2-mo-old mice $[n=7]$ and $163 \pm 14 \%$ in 12 -mo-old mice [ $n=5]$, Student $t$-test, $P=0.76$ ). While monitoring the fEPSP for $4 \mathrm{~h}$ after LTP induction, we found that the LTP induced by a single train $(100 \mathrm{~Hz}, 1 \mathrm{sec})$ was improved in the older group. Four hours after the application of this stimulation, the fEPSP amplitude was greater in 12-mo-old mice $(182 \pm 22 \%, n=5)$ than in young mice (113 $\pm 4 \%, n=8$, Student $t$-test, $P<0.001)$.

The main goal of this research was to explore the possibility that input specificity of LTP could vanish with aging. With that aim in view, two distinct bundles of Schaffer collaterals were stimulated (S1 and S2) and the responses (fEPSP) that both of them evoked in a same group of CA1 pyramidal neurons were recorded (Fig. 2A1,A2). A prerequisite for this type of experiment is to make sure that the two bundles of afferent fibers excited via the two stimulating electrodes are distinct. This independence of the two synaptic inputs, S1 and S2, was ascertained by the lack of crossed paired-pulse facilitation (PPF) (Fig. 2B1,B2). We checked that this strategy was not biased by a potential difference in PPF with age. PPF observed in young mice $(170 \pm 3 \%, n=39)$ was not different from that recorded in older mice (162 $\pm 4 \%, n=16$, Student $t$-test, $P=0.11)$. S1 was used to deliver the LTP-triggering stimulus whereas test stimuli only were applied through S2. In young mice $(2 \mathrm{mo})$, we confirmed the well-established input selectivity of LTP (Fig. 2C) (Bliss and Lomo 1973; Andersen et al. 1977). When four trains ( $1 \mathrm{sec}, 100 \mathrm{~Hz}, 5 \mathrm{~min}$ apart) were applied 
A

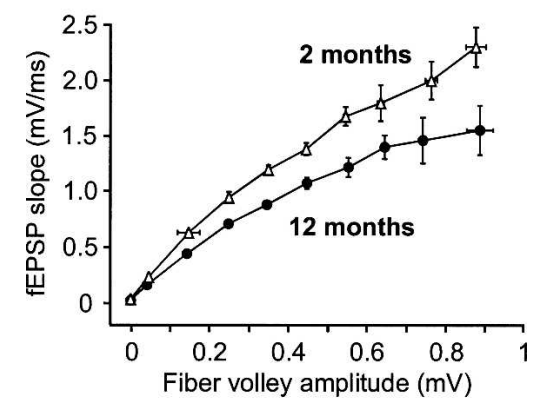

B

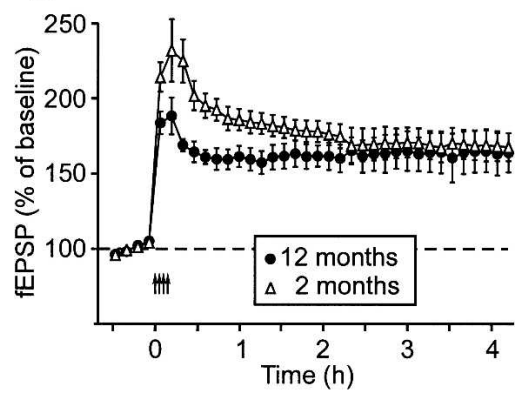

C

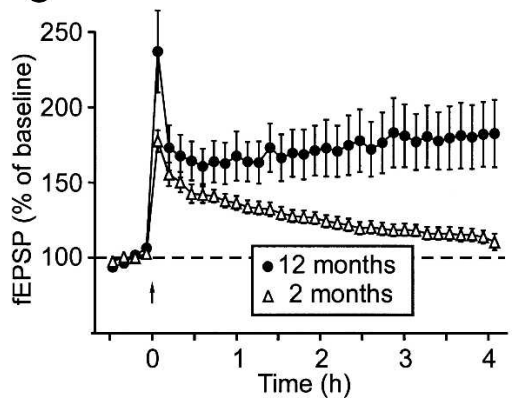

Figure 1. Comparison of basal synaptic transmission and LTP elicited in young mice $(2 \mathrm{mo})$ and in older animals $(12 \mathrm{mo})$. All the experiments were performed in an interface chamber (FST) at $28^{\circ} \mathrm{C}$. Slices were perfused with artificial cerebro-spinal fluid (ACSF) with the following composition: $124 \mathrm{mM} \mathrm{NaCl}, 5 \mathrm{mM} \mathrm{KCl}, 26 \mathrm{mM} \mathrm{NaHCO}_{3}, 1.0 \mathrm{mM} \mathrm{NaH}_{2} \mathrm{PO}_{4}$, $2.4 \mathrm{mM} \mathrm{CaCl}, 1.3 \mathrm{mM} \mathrm{MgSO}$, and $10 \mathrm{mM}$ glucose. The ACSF was aerated with $95 \% \mathrm{O}_{2}$ and $5 \% \mathrm{CO}_{2}$. The rate of flow of the perfused liquid was $1 \mathrm{~mL} / \mathrm{min}$. The duration of the stimulation pulses was $0.08 \mathrm{msec}$. Slices that showed maximal fEPSPs $<2 \mathrm{mV}$ were rejected. Stimulation intensity was adjusted to elicit fEPSP amplitudes that were around $40 \%$ of maximum size. $(A)$ The relationship between the slope of the fEPSP and the fiber volley size is plotted for 2-mo-old $(n=75)$ and 12-mo-old $(n=58)$ mice. The fiber volley sizes were lumped in successive groups of $0.1 \mathrm{mV}$ range starting from $0 \mathrm{mV}$. Data points represent mean \pm SEM. The difference between the two groups was significant. (B) LTP was induced by four trains of tetanic stimulation 5 min apart and recorded using a test pulse delivered four times $(0.2 \mathrm{~Hz})$ every $8 \mathrm{~min}$. There was no statistical difference between the LTP elicited in slices from mice aged 2 $\mathrm{mo}(n=7)$ and $12 \mathrm{mo}(n=5)$. (C) LTP induced by a single train in slices from animals aged $2 \mathrm{mo}(n=8)$ or $12 \mathrm{mo}(n=5)$. This stimulus triggered a short-lasting LTP in young mice, a long-lasting one in older animals.

through S1, an LTP developed in the synapses tested via S1 (168 $\pm 10 \%$ of baseline $4 \mathrm{~h}$ after induction, $n=7$, Fig. $2 \mathrm{C}$, filled circles), while the strength of the synapses tested via $\mathrm{S} 2$ remained unchanged (104 $\pm 3 \%$ of baseline, $n=7$, Fig. $2 \mathrm{C}$, red squares). As a control, the amplitude of the fEPSP was also monitored in slices where no high frequency stimulation was applied (Fig. 2C, open circles). This control curve did not significantly deviate from baseline over time (one-way ANOVA on ranks with one repeated measure, $P=0.14$ ). At a time corresponding to $4 \mathrm{~h}$ after application of LTP-inducing stimulus (where applied) the slope of the fEPSP was higher in response to $\mathrm{S} 1$ stimulation than in response to S2 stimulation, the latter being not different from that measured in the control situation (one-way ANOVA on ranks followed by post-hoc analysis, $P<0.05$ ).

The situation was totally different in mice aged 12 mo. Application of four trains of stimulation through S1 triggered not only an LTP in the synapses tested via S1, but also a progressively developing increase in the strength of the synapses tested via S2 (Fig. 2D). Four hours after induction, the fEPSP was $163 \pm 14 \%$ of baseline in response to S1 (Fig. 2D, filled circles, $n=5$ ) and $160 \pm 9 \%$ of baseline in response to S2 (Fig. 2D, red squares). In the control situation in older animals the fEPSP increased over time (one-way ANOVA on ranks with one repeated measure, $P<0.001, n=8$ ) but only slightly, reaching $119 \pm 4 \%$ of baseline at time $4 \mathrm{~h}$ (Fig. 2D, open circles). One-way ANOVA followed by
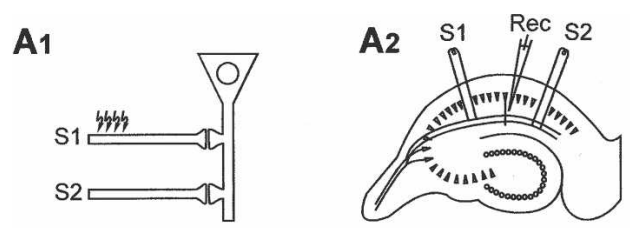

B1
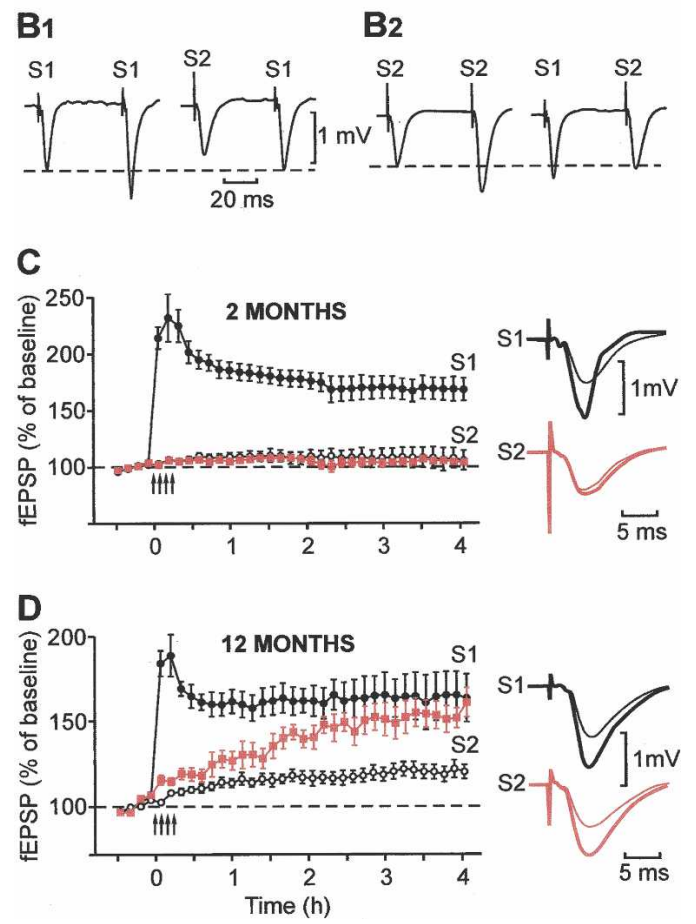

Figure 2. Loss of input specificity of LTP with aging. $(A 1, A 2)$ Sketch showing the two independent synaptic inputs $S 1$ and $S 2$ to the same neuronal population. S1 was tetanized at the moment of LTP induction. S2 was stimulated only with test pulses. $(B 1, B 2)$ Independence of $S 1$ and S2 was ascertained by the lack of crossed paired-pulse facilitation. Two stimulations were applied with a 50-msec interval. A representative illustration is given in $B 1$ and $B 2$. An increase of up to $10 \%$ was tolerated. $(C, D)$ Stimulation of $S 1$ revealed a robust LTP after tetanization of S1 both in young and old mice (filled circles). In contrast, after induction of LTP in S1, stimulation of $S 2$ revealed stable recordings in 2-mo-old mice $(C)$ but responses increasing over time in 12-mo-old animals (red squares, $D$ ). (Insets) Representative potentials recorded immediately before (thin line) and $4 \mathrm{~h}$ after (thick line) tetanization. The fEPSP slope was also monitored in slices where no high frequency stimulation was applied (control, open circles). 
post-hoc analysis confirmed that the responses measured at time $4 \mathrm{~h}$ were not different in response to S1 and S2 stimulations and that these responses were both different from that recorded in the control situation $(P<0.05)$.

In the hippocampus, aging is accompanied by two major $\mathrm{Ca}^{++}$dysregulations: (1) an increase in $\mathrm{Ca}^{++}$influx through L-type voltage-dependent calcium channels (L-VDCC) (Thibault and Landfield 1996; Shankar et al. 1998; Veng et al. 2003) and (2) an increase in $\mathrm{Ca}^{++}$-induced $\mathrm{Ca}^{++}$release from the endoplasmic reticulum (Kumar and Foster 2004; Gant et al. 2006). These changes were demonstrated to be responsible for several hippocampal electrophysiological changes, including increases in slow afterhyperpolarization and spike accommodation (Gant et al. 2006). Here, we demonstrated that they are also responsible for the loss of input specificity in LTP. Nifedipine $(10 \mu \mathrm{M})$, a blocker of L-VDCC, was applied $15 \mathrm{~min}$ before, during, and $15 \mathrm{~min}$ after delivering four trains via the S1 pathway on slices from 12month-old mice (Fig. 3A). Such a treatment did not prevent this strong stimulus applied through S1 from triggering a robust LTP in the stimulated synapses. The slope of the fEPSP reached $152 \pm 10 \%$ of baseline (filled circles, $n=5$ ) $4 \mathrm{~h}$ after induction, which was not different from that measured in the absence of nifedipine $(163 \pm 14, P=0.73)$. In contrast, nifedipine prevented this increase in fEPSP slope from spreading to the control pathway (S2). Four hours after the LTP induction, the value of the fEPSP slope tested via the S2 input (105 $\pm 7 \%$ of baseline, red squares) was lower than that measured in the absence of nifedipine $(160 \pm 9 \%$ of baseline, Student $t$-test, $P<0.001)$

Thapsigargin $(1 \mu \mathrm{M})$, an inhibitor of SERCA which induces a depletion of endoplasmic $\mathrm{Ca}^{++}$stores, was applied on slices from the beginning of the recovery period to the end of the experiment (Fig. 3B). This treatment had a similar effect to that of nifedipine. Four hours after LTP induction via S1, the fEPSP slopes were similar in the synapses tested via S1, whether thapsigargin was present or not $(178 \pm 10 \%$ [filled circles, $n=5$ ] vs. $168 \pm 10 \%$ of baseline, Student $t$-test, $P=0.49$ ). In contrast, the fEPSP slope of the synapses tested via S2 was lower than that recorded in the absence of thapsigargin $(123 \pm 10 \%$ [red squares] vs. $160 \pm 9 \%$ of baseline, Student $t$-test, $P<0.05$ ).

We also checked the effect of D-APV, an NMDA receptor antagonist, on input selectivity of LTP on slices from 12-mo-old mice (Fig. 3C). As expected, D-APV suppressed LTP in the S1 pathway. Interestingly, D-APV also prevented any development of LTP in the S2 pathway.

Thus, we compared the input selectivity of LTP in two groups of mice: one cohort of younger animals $(2 \mathrm{mo})$ and a second cohort of older animals, aged $12 \mathrm{mo}$. Spatial memory has been demonstrated to be impaired at the age of 12 mo (Bach et al. 1999). We found that, whereas the robustness of the L-LTP triggered by four trains of tetanic stimulation was not impaired in our group of older animals, its input selectivity, which theoretical modeling considers as crucial for encoding memories in neuronal networks, was lost in 12-mo-old animals. As we further demonstrated this deficit to be reduced by blocking different $\mathrm{Ca}^{++}$-related processes, it could be the missing link between agerelated $\mathrm{Ca}^{++}$dysregulations and the decline in memory associated with aging. We also found that a stimulus which is well known to induce an S-LTP and not an L-LTP in young mice (i.e., a single train of high frequency stimulation) triggered an L-LTP in older animals. This phenomenon is related to the one recently observed by Huang and Kandel (2006) using another pattern of presynaptic stimulation.

How could the known $\mathrm{Ca}^{++}$dysregulations associated with aging explain the loss of input specificity? A first possibility results from the fact that VDCCs play a role in LTP in aged mice that they do not in younger animals. In young animals, APV, an
A
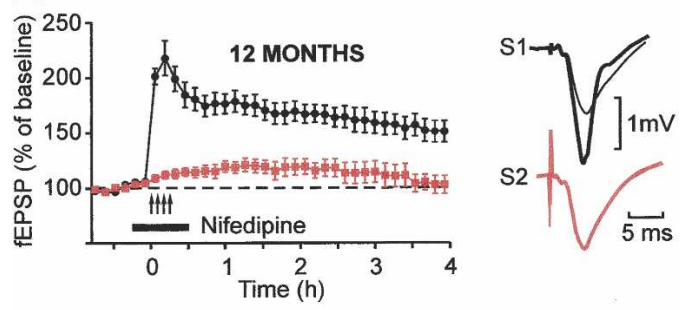

B
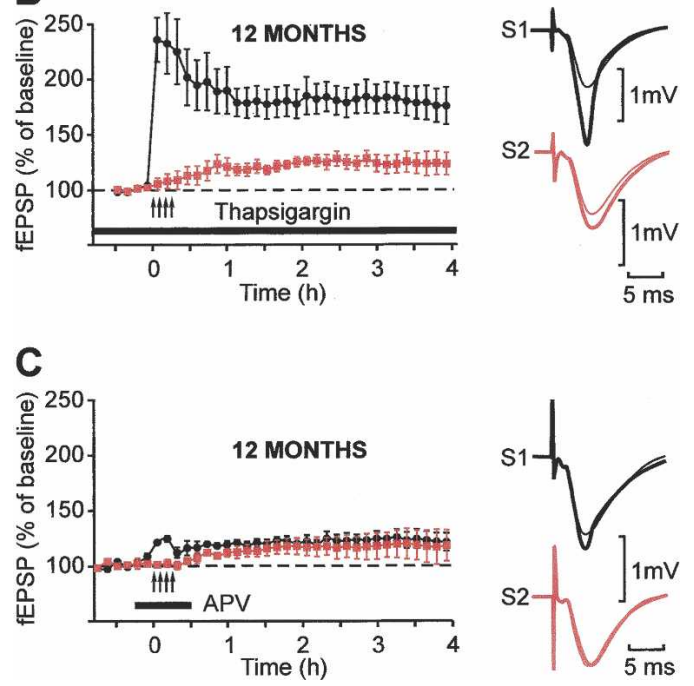

Figure 3. The loss of input specificity of LTP in older animals is a result of the $\mathrm{Ca}^{++}$dysregulations known as biomarkers of aging. (A-C) LTP was induced in hippocampal slices from 12-mo-old mice by application of four trains on the $S 1$ pathway in presence of either nifedipine, a blocker of L-VDCC $(A)$, thapsigargin, a blocker of SERCA $(B)$, or D-APV, an inhibitor of NMDA receptors $(C)$. $(A, B)$ Nifedipine (Tocris) and thapsigargin (Tocris) were both prepared as concentrated stock solutions in dimethyl sulfoxide (DMSO) and then diluted to $0.1 \%$ in ACSF for nifedipine and to $0.01 \%$ in ACSF for thapsigargin to give their final concentrations. Because of the light sensitivity of nifedipine, all experiments using this drug were conducted in a darkened room. Nifedipine $(10 \mu \mathrm{M})$ was applied from 15 min before, during, and 15 min after the stimulation trains and thapsigargin $(1 \mu \mathrm{M})$ from the end of slicing till the end of the experiment. Neither nifedipine $(n=6)$ nor thapsigargin $(n=5)$ impaired LTP induced in the S1 pathway. However, the increase in fEPSP usually observed in older animals in the test pathway (S2) after tetanic stimulation of $\mathrm{S} 1$ was greatly reduced (red squares). (C) D-APV ( $50 \mu \mathrm{M}$, Tocris) was applied 15 min before, during, and 15 min after induction. D-APV suppressed any development of LTP both in the stimulated pathway and in the unstimulated pathway. Both in the S1 and S2 pathways, the increases in fEPSP slope $(122 \pm 8 \%$ of baseline for the S1 pathway and $117 \pm 15 \%$ of baseline for the S2 pathway, $n=4$ ) were not different from those recorded in the absence of any stimulation trains $(119 \pm 4 \%$, Student $t$-test, $P=0.76$ for the $S 1$ pathway and $P=0.84$ for the $S 2$ pathway).

NMDA receptor blocker, completely prevents a $100-\mathrm{Hz}$ tetanus applied to the Schaffer collaterals from inducing LTP. However, when NMDARs are completely blocked by APV, a stronger tetanus $(200 \mathrm{~Hz})$ induces an APV-insensitive LTP, which can be prevented by applying nifedipine (Cavus and Teyler 1996). Using this type of protocol, it was demonstrated that, with aging, the VDCC-dependent component of LTP increased while its NMDAdependent component diminished (Shankar et al. 1998). More precisely, the density of functional L-type VDCC increases in mammalian CA1 hippocampal neurons during aging (Thibault and Landfield 1996; Veng et al. 2003). The loss of input specificity observed in aged animals could be related to this up- 
regulation of the VDCCs with aging. In both young and aged neurons, the depolarization induced in some dendritic spines spreads electrotonically to the neighboring spines with decay. In young neurons, the depolarization left in the remote spines is not sufficient to open a number of L-VDCCs large enough to induce a significant entry of $\mathrm{Ca}^{++}$. However, in aged neurons where the density of functional L-VDCCs is increased, this could be the case. According to this L-VDCC hypothesis, the LTP triggered in a pathway remote from the stimulated pathway is thus due to an entry of $\mathrm{Ca}^{++}$through the L-VDCCs. Therefore, one could expect that D-APV could leave unchanged the LTP elicited in the unstimulated pathway. This is not the case (Fig. 3C). This is likely due to the fact that the blockage of the NMDA receptors by DAPV reduces the amplitude of the depolarization at the activated dendritic spines (see also Morgan and Teyler 2001). As a result, the depolarization left in the remote dendritic spines after electrotonic spread is no longer sufficient to open there the VDCCs.

A second possibility is related to the intracellular $\mathrm{Ca}^{++}$stores. A local stimulation of the Schaffer collaterals not only triggers a rise in $\left[\mathrm{Ca}^{++}\right]_{i}$ in the activated dendritic spines (Sabatini et al. 2002) but also elicits an intradendritic $\left[\mathrm{Ca}^{++}\right]_{\mathrm{i}}$ rise that propagates as a wave along the dendrites of CA1 neurons, but only at short distance (not exceeding $70 \mu \mathrm{m}$ ) (Jäger et al. 2002). This propagation of $\mathrm{Ca}^{++}$waves occurs along the dendritic endoplasmic reticulum using IP3 receptors (Nishiyama et al. 2000). The existence of this short-distance $\mathrm{Ca}^{++}$wave propagation explains that there is no input specificity at a distance of $<70 \mu \mathrm{m}$ (Engert and Bonhoeffer 1997). In other words, in young neurons, synapses in close proximity to a site of potentiation are also potentiated regardless of their own history of activation, whereas synapses far away show no potentiation (Engert and Bonhoeffer 1997). Using certain experimental conditions, Jaffe and Brown (1994) were able to induce increases in $\left[\mathrm{Ca}^{++}\right]_{i}$ that propagated throughout the whole dendritic tree. The $\mathrm{Ca}^{++}$-induced release of $\mathrm{Ca}^{++}$from the endoplasmic reticulum is increased in aged animals (Gant et al. 2006). As a result, it can be anticipated that the short-distance wave-like propagation of $\left[\mathrm{Ca}^{++}\right]_{\mathrm{i}}$ increase observed in young neurons could be transformed into long-distance propagation in aged neurons. Moreover, the increased density of functional VDCCs in aged neurons could also favor this mechanism, as $\mathrm{Ca}^{++}$ entry through VDCCs can replenish intracellular $\mathrm{Ca}^{++}$stores (Jaffe and Brown 1994). According to this second possibility (intracellular $\mathrm{Ca}^{++}$store hypothesis), the LTP triggered in a pathway at distance from the stimulated pathway is due to a $\mathrm{Ca}^{++}$wave initiated by the $\mathrm{Ca}^{++}$ions entered via the NMDA receptors at the stimulated site. In this case, application of D-APV should also cause a suppression of any LTP in the remote pathway. This is what we observed (Fig. 3C).

In conclusion, we have found a new electrophysiological biomarker of aging that seems to be the result of well-established $\mathrm{Ca}^{++}$dysregulations associated with aging and that could explain age-related memory loss.

\section{Acknowledgments}

We thank Peter Nguyen for technical advice at the beginning of this work. We thank Christiane Busson for assistance on the figures and Ramona Shelby for correcting the English. This investigation was supported by the Queen Elisabeth Fund for Medical Research and by the Belgian National Fund for Scientific Research. Laurence Ris is a Research Associate of the Belgian National Fund for Scientific Research.

\section{References}

Abel, T., Nguyen, P.V., Barad, M., Deuel, T.A., Kandel, E.R., and Bourtchouladze, R. 1997. Genetic demonstration of a role for PKA in the late phase of LTP and in hippocampus based long-term memory. Cell 88: 615-626.

Andersen, P., Sundberg, S.H., Sveen, O., and Wigstrom, H. 1977. Specific long-lasting potentiation of synaptic transmission in hippocampal slices. Nature 266: 736-737.

Bach, M.E., Barad, M., Son, H., Zhuo, M., Lu, Y.F., Shih, R., Mansuy, I., Hawkins, R.D., and Kandel, E.R. 1999. Age-related defects in spatial memory are correlated with defects in the late phase of hippocampal long-term potentiation in vitro and are attenuated by drugs that enhance the cAMP signaling pathway. Proc. Natl. Acad. Sci. 96: 5280-5285.

Barnes, C.A., Rao, G., Foster, T.C., and McNaughton, B.L. 1992. Region specific age effects on AMPA sensitivity: Electrophysiological evidence for loss of synaptic contacts in hippocampal field CA1. Hippocampus 2: 457-468.

Bliss, T.V. and Lomo, T. 1973. Long-lasting potentiation of synaptic transmission in the dentate area of the anaesthetized rabbit following stimulation of the perforant path. J. Physiol. 232: 331-356.

Brody, H. 1955. Organization of the cerebral cortex. III. A study of aging in the human cerebral cortex. J. Comp. Neurol. 102: 511-516.

Burke, S.N. and Barnes, C.A. 2006. Neural plasticity in the ageing brain. Nat. Rev. Neurosci. 7: 30-40.

Cavus, I. and Teyler, T. 1996. Two forms of long-term potentiation in area CA1 activate different signal transduction cascades. $J$. Neurophysiol. 76: 3038-3047.

Deupree, D.L., Bradley, J., and Turner, D.A. 1993. Age-related alterations in potentiation in the CA1 region in F344 rats. Neurobiol. Aging 14: $249-258$.

Engert, F. and Bonhoeffer, T. 1997. Synapse specificity of long-term potentiation breaks down at short distances. Nature 388: 279-284.

Gant, J.C., Sama, M.M., Landfield, P.W., and Thibault, O. 2006. Early and simultaneous emergence of multiple hippocampal biomarkers of aging is mediated by $\mathrm{Ca}^{2+}$ - induced $\mathrm{Ca}^{2+}$ release. J. Neurosci. 26: 3482-3490.

Huang, Y.Y. and Kandel, E.R. 1994. Recruitment of long-lasting and protein kinase A-dependent long-term potentiation in the CA1 region of hippocampus requires repeated tetanization. Learn. Mem. 1: 74-82.

Huang, Y.Y. and Kandel, E.R. 2006. Age-related enhancement of a protein synthesis-dependent late phase of LTP induced by low frequency paired-pulse stimulation in hippocampus. Learn. Mem. 13: $298-306$.

Jaffe, D.B. and Brown, T.H. 1994. Metabotropic glutamate receptor activation induces calcium waves within hippocampal dendrites. $J$. Neurophysiol. 72: 471-474.

Jäger, T., Behnisch, T., and Reymann, K.G. 2002. High frequency stimulation-induced dendritic calcium waves in rat hippocampal neurons. Neurosci. Lett. 335: 103-106.

Kumar, A. and Foster, T.C. 2004. Enhanced long-term potentiation during aging is masked by processes involving intracellular calcium stores. J. Neurophysiol. 91: 2437-2444.

Landfield, P.W. and Pitler, T.A. 1984. Prolonged $\mathrm{Ca}^{2+}$-dependent afterhyperpolarizations in hippocampal neurons of aged rats. Science 226: 1089-1092.

Landfield, P.W., Pitler, T.A., and Applegate, M.D. 1986. The effects of high $\mathrm{Mg}^{2+}$-to- $\mathrm{Ca}^{2+}$ ratios on frequency potentiation in hippocampal slices of young and aged rats. J. Neurophysiol. 56: 797-811.

Moore, C.I., Browning, M.D., and Rose, G.M. 1993. Hippocampal plasticity induced by primed burst, but not long-term potentiation, stimulation is impaired in area CA1 of aged Fischer 344 rats. Hippocampus 3: 57-66.

Morgan, S.L. and Teyler, T.J. 2001. Electrical stimuli patterned after theta-rhythm induce multiple forms of LTP. J. Neurophysiol. 86: 1289-1296.

Nguyen, P.V. and Kandel, E.R. 1997. Brief theta-burst stimulation induces a transcription-dependent late phase of LTP requiring cAMP in area CA1 of the mouse hippocampus. Learn. Mem. 4: 230-243.

Nishiyama, M., Hong, K., Mikoshiba, K., Poo, M., and Kato, K. 2000. Calcium stores regulate the polarity and input specificity of synaptic modification. Nature 408: 584-588.

Norris, C.M., Halpain, S., and Foster, T.C. 1998. Reversal of age-related alterations in synaptic plasticity by blockade of L-type $\mathrm{Ca}^{2+}$ channels. J. Neurosci. 18: 3171-3179.

Rosenzweig, E.S. and Barnes, C.A. 2003. Impact of aging on hippocampal function: Plasticity, network dynamics, and cognition. Prog. Neurobiol. 69: 143-179.

Sabatini, B.L., Oertner, T.G., and Svoboda, K. 2002. The life cycle of $\mathrm{Ca}^{2+}$ ions in dendritic spines. Neuron 33: 439-452.

Scheibel, A.B. 1979. The hippocampus: Organizational patterns in health and senescence. Mech. Ageing Dev. 9: 89-102.

Scheibel, M.E., Lindsay, R.D., Tomiyasu, U., and Scheibel, A.B. 1976. Progressive dendritic changes in the aging human limbic system. 
Exp. Neurol. 53: 420-430.

Shankar, S., Teyler, T.J., and Robbins, N. 1998. Aging differentially alters forms of long-term potentiation in rat hippocampal area CA1. J. Neurophysiol. 79: 334-341.

Thibault, O. and Landfield, P.W. 1996. Increase in single L-type calcium channels in hippocampal neurons during aging. Science 272: $1017-1020$.

Thibault, O., Hadley, R., and Landfield, P.W. 2001. Elevated postsynaptic $\left[\mathrm{Ca}^{2+}\right]_{\mathrm{i}}$ and L-type calcium channel activity in aged hippocampal neurons: Relationship to impaired synaptic plasticity. J. Neurosci. 21: 9744-9756.

Veng, L.M., Mesches, M.H., and Browning, M.D. 2003. Age-related working memory impairment is correlated with increases in the L-type calcium channel protein $\alpha 1 \mathrm{D}\left(\mathrm{Ca}_{\mathrm{v}} 1.3\right)$ in area CA1 of the hippocampus and both are ameliorated by chronic nimodipine treatment. Brain Res. Mol. Brain Res. 110: 193-202.

Zipser, D. and Andersen, R.A. 1988. A back-propagation programmed network that stimulates response properties of a subset of posterior parietal neurons. Nature 331: 679-684.

Received October 17, 2006; accepted in revised form January 9, 2007. 


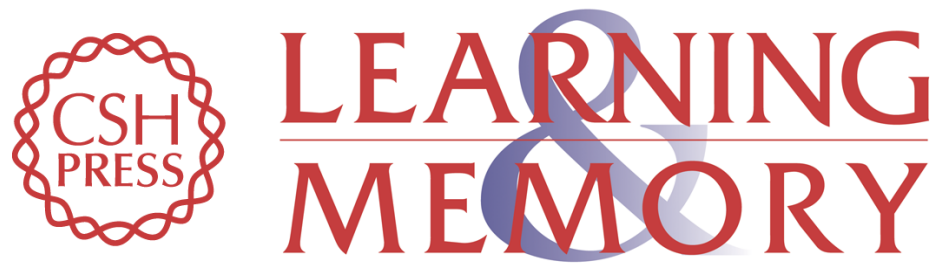

\section{Synapse specificity of long-term potentiation breaks down with aging}

Laurence Ris and Emile Godaux

Learn. Mem. 2007, 14:

Access the most recent version at doi:10.1101//m.451507

References This article cites 32 articles, 9 of which can be accessed free at:

http://learnmem.cshlp.org/content/14/3/185.full.html\#ref-list-1

License

Email Alerting Receive free email alerts when new articles cite this article - sign up in the box at the Service top right corner of the article or click here. 